\title{
PERANCANGAN SISTEM MONITORING TINGKAT KEKERUHAN AIR SECARA REALTIME MENGGUNAKAN SENSOR TSD-10
}

\author{
Muhammad Faisal ${ }^{1}$, Harmadi ${ }^{2}$, Dwi Puryanti ${ }^{2}$ \\ ${ }^{1}$ Program Pascasarjana FMIPA Universitas Andalas \\ ${ }^{2}$ Jurusan Fisika, FMIPA Universitas Andalas, Padang 25163 \\ e-mail :1faisal.fs031@gmail.com;2harmadi@fmipa.unand.ac.id
}

\begin{abstract}
ABSTRAK
Sebuah sistem monitoring tingkat kekeruhan air secara realtime dengan menggunakan sensor TSD-10 telah dirancang. Tingkat kekeruhan air diukur dengan memanfaatkan perubahan tegangan sensor akibat perubahan kekeruhan. Perancangan sistem monitoring ini terdiri dari perancangan perangkat keras dan perangkat lunak. Perangkat keras terdiri dari sistem sensor, driver motor dc menggunakan IC L293D, sistem minimum mikrokontroler ATmega8, dan modul USBtoSerial. Perancangan perangkat lunak menggunakan program BASCOM 2.0.75 untuk mikrokontroler dan Borland Delphi 7 untuk sistem GUI. Perangkat yang dirancang mampu melakukan pengukuran secara realtime dan menampilkan dalam bentuk angka serta menyimpan dalam bentuk database. Pengumpulan data dilakukan dengan membandingkan sistem yang dirancang dengan alat ukur kekeruhan standar $\mathrm{HACH} 2100 \mathrm{~N}$. Data yang diperoleh melalui pengukuran dianalisis menggunakan teori kesalahan dan interpolasi. Berdasarkan analisis yang dilakukan didapatkan tegangan keluaran sensor berkurang dengan kenaikan kekeruhan air dengan sensitivitas 2 $\mathrm{mV} / \mathrm{NTU}$. Derajat korelasi linier sensor didapatkan sebesar $\mathrm{R}^{2}=0,99$ dan persentase ketepatan rata-rata pengukuran $93,49 \%$.
\end{abstract}

Kata kunci : Sistem Monitoring, Tingkat kekeruhan air, Sensor TSD-10

\begin{abstract}
A real time monitoring system for water turbidity levels using sensor TSD-10 has been designed. Water turbidity levels are measured through the utilization of voltage changes data in sensor triggered by turbidity alteration. The design of this monitoring system consists of hardware and software parts. The hardware comprises a sensor system, a dc motor driver using an IC L293D, a minimum system of microcontroller ATmega8 and USBtoSerial module. Meanwhile, the software uses BASCOM program 2.0.75 for microcontroller and Borland Delphi 7 in the GUI system. This designed device is able to perform real-time measurement, to display numeric form, and to store a database. Data collection is done by comparing the designed system with a standard turbidity measuring instrument named HACH $2100 \mathrm{~N}$. The data obtained through the measurement are analyzed using errors theories and interpolation. Based on the analysis, it is found that the output voltage of sensor decreases with the increase of turbidity with a sensitivity of $2 \mathrm{mV} / \mathrm{NTU}$. The degree of sensor linearity correlation is determined in $\mathrm{R}^{2}=0.99$. And, the percentage accuracy of average measurement is 93.49 .
\end{abstract}

Keywords: System Monitoring, level of turbidity, sensor TSD-10

\section{PENDAHULUAN}

Air merupakan unsur terpenting bagi tubuh manusia dengan rasio perbandingan sebesar $60 \%$ hingga $70 \%$ dibandingkan dengan unsur yang lain. Besarnya rasio perbandingan ini tentu menjadi suatu keharusan untuk memperhatikan kelayakan air yang digunakan untuk

JURNAL ILMU FISIKA (JIF), VOL 8 NO 1, MARET 2016 
dikonsumsi. Secara fisis air bersih diindikasikan dengan keadaannya yang bening, tidak berwarna dan tidak berbau. Kondisi seperti ini terjadi jika air tidak dikotori oleh bahan organik dan anorganik. Sedangkan secara optis, air yang tercampur oleh bahan pengotor, keadaanya akan mengalami perubahan, mungkin menjadi berwarna atau menjadi keruh (Peslinof, 2013).

Tingkat kekeruhan air merupakan salah satu parameter yang dijadikan kelayakan air baik untuk diminum. Menurut International Organization for Standardization (1999) kekeruhan adalah suatu keadaan dimana transparansi suatu zat cair berkurang akibat kehadiran zat-zat lainnya. Kehadiran zat-zat yang dimaksud terlarut dalam zat cair dan membuatnya seperti berkabut atau tidak jernih. Menurut Peraturan Menteri Kesehatan Republik Indonesia nomor 492 tahun 2010 tentang persyaratan kualitas air minum yang aman bagi kesehatan adalah air yang apabila memenuhi persyaratan fisika, mikrobiologis, kimiawi dan radioaktif yang dimuat dalam parameter wajib dan parameter tambahan. Dalam peraturan ini disebutkan bahwa kadar maksimal kekeruhan air yang baik untuk dikonsumsi adalah 5 NTU (Nephelometric Turbidity Unit).

Tingkat kekeruhan air adalah suatu studi dari sifat-sifat optis yang menyebabkan cahaya yang melewati air menjadi terhambur dan terserap dari cahaya yang dipancarkan dalam garis lurus (Fairuz dan Zubir, 2009). Kekeruhan menyebabkan air menjadi seperti berkabut atau berkurangnya transparansi dari air. Arah dari berkas cahaya yang dipancarkan akan berubah ketika cahaya berbenturan dengan partikel di dalam air. Jika level kekeruhan rendah maka sedikit cahaya yang akan dihamburkan dan dibiaskan dari arah asalnya.

Tingkat kekeruhan air (turbidity) dapat diketahui dengan menggunakan turbidimeter. Perancangan turbidimeter sebagai alat yang digunakan untuk mengukur tingkat kekeruhan air didasarkan pada beberapa metode. Metode pengukuran tingkat kekeruhan zat cair dibedakan menurut intensitas cahaya mana yang diukur, cahaya yang diteruskan, cahaya yang dihamburkan atau kedua-duanya (Lambrou et al, 2008). Umumnya ada dua tipe dari turbidimeter, pertama absorptiometer yaitu pengukuran penyerapan (pelemahan) dari cahaya yang melewati suatu larutan. Kedua nephelometer yaitu pengukuran hamburan cahaya yang melewati suatu larutan. Teknik atau metode pengukuran tingkat kekeruhan air dapat dilihat pada Gambar 1.

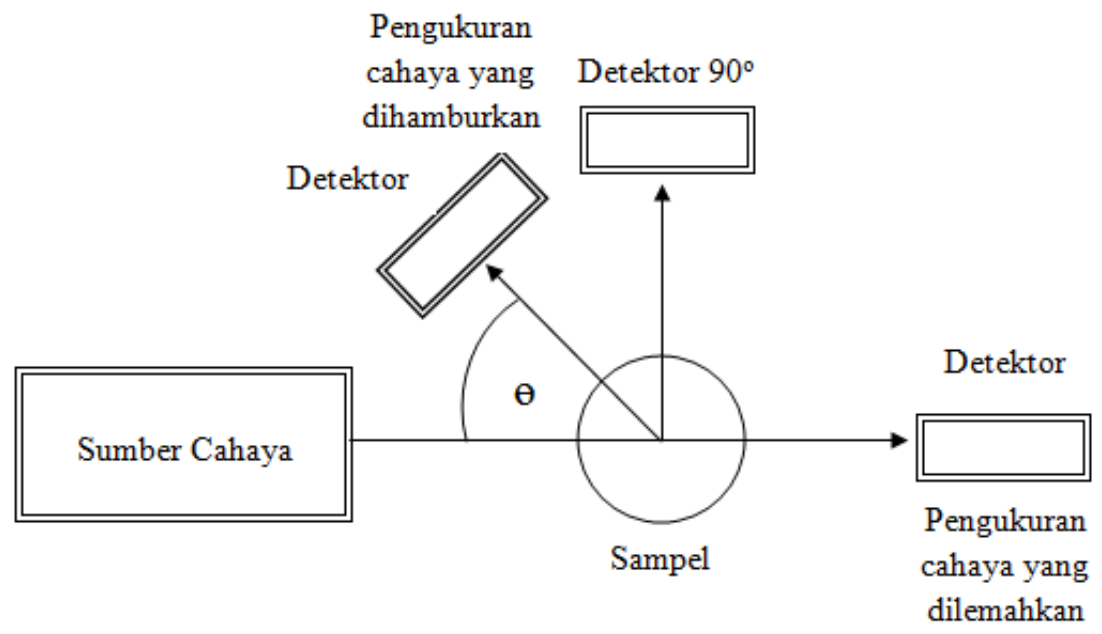

Gambar 1 Teknik pengukuran tingkat kekeruhan air

Pada tahun 2013 Nuzula dan Endarko membuat sebuah alat ukur kekeruhan air dengan menggunakan sensor fotodioda. Sensor fotodioda dan LED (Light Emitting Diode) 
diletakkan sejajar membentuk sudut $180^{\circ}$ dalam sebuah wadah sebagai tempat sampel. Alat yang dihasilkan mampu melakukan pengukuran dengan rentang dari 0 hingga 200 NTU. Somasundaram dan Ediosn pada tahun 2013 juga merancang sebuah turbidimeter dengan menggunakan sensor LDR Light Dependent Resistor). Alat yang dihasilkan dapat melakukan pengukuran pada batas pengukuran dengan nilai referensi tertentu bukan pada suatu rentang pengukuran. Penelitian sejenis juga telah dilakukan oleh $\mathrm{Hu}$ dkk pada tahun 2014 dengan menggunakan sensor fotodioda. Alat yang dirancang dapat dioperasikan secara in-situ dan memiliki rentang pengukuran 0 hingga 25 FTU (Formazin Turbidity Unit).

Turbidimeter yang memanfaatkan pengukuran pelemahan intensitas cahaya berhubungan dengan prinsip hukum Lambert-Beer. Hukum Lambert-Beer menjelaskan hubungan pelemahan dari intensitas cahaya terhadap sifat-sifat material yang dilewati oleh berkas cahaya. Bila suatu sumber cahaya monokromatik melewati medium transparan, maka intensitas cahaya yang diteruskan berkurang dengan bertambahnya ketebalan medium yang mengabsorpsi. Selain itu intensitas cahaya yang diteruskan berkurang secara eksponensial dengan bertambahnya konsentrasi spesimen yang menyerap cahaya tersebut. Fenomena ini dinyatakan oleh hukum Lambert- Beer seperti dirumuskan pada Persamaan 2.1(Hardesty dan Attili, 2010).

$$
I=I_{0} \exp (-a l c) \quad \text { atau } \quad A=a l c
$$

Dengan $I$ merupakan intensitas cahaya yang diteruskan $\left(\mathrm{mW} / \mathrm{cm}^{2}\right), I_{o}$ merupakan intensitas cahaya yang dipancarkan $\left(\mathrm{mW} / \mathrm{cm}^{2}\right), \varepsilon$ absorpsitivitas $\left(\mathrm{M}^{-1} \mathrm{~cm}^{-1}\right), l$ merupakan ketebalan medium penyerap $(\mathrm{cm}), c$ merupakan konsentrasi zat penyerap (Molar) dan $A$ merupakan absorbansi (serapan).

Besar nilai absorbansi jika dihubungkan dengan nilai intensitas cahaya datang dengan cahaya yang diteruskan merupakan sebuah fungsi logaritma seperti pada Persamaan 2.2 (Hardesty dan Attili, 2010).

$$
A=\log \frac{1}{1}
$$

Nilai absorbansi ini kemudian dijadikan sebagai analisis sinyal untuk menentukan tingkat kekeruhan air (turbiditi) yang merupakan kebalikan dari absorpsi seperti pada Persamaan 2.3(Santos et al, 2011).

$$
\operatorname{Turbt} \operatorname{tg} t t=-\log \left(\frac{t}{V_{\alpha}}\right)
$$

\section{METODE PENELITIAN}

Penelitian terhadap sistem monitoring tingkat kekeruhan air menggunakan sensor TSD-10 ini dilakukan di Laboratorium Elektronika dan Instrumentasi Jurusan Fisika FMIPA Universitas Andalas serta di Instalasi Pengolahan Air Perusahaan Daerah Air Minum Kota Padang. Perancangan sistem monitoring ini terdiri dari perangkat keras dan lunak yang dapat memonitor tingkat kekeruhan air dengan menggunakan sensor TSD-10, mikrokontroler ATmega8 sebagai pengolah, perancangan Graphical User Interface (GUI) sebagai media penampil dan penyimpanan data serta menggunakan bahasa pemograman BASIC dan Delphi untuk perangkat lunak. 


\subsection{Blok Diagram Sistem Monitoring}

Sistem monitoring tingkat kekeruhan air dengan menggunakan sensor kekeruhan TSD-10 ini menggunakan prinsip pengukuran pelemahan intensitas cahaya yang diterima oleh sensor. Dalam modul sensor ini sudah tersedia LED sebagai sumber cahaya dan fototransistor sebagai penerimanya. Ketika sensor dicelupkan ke dalam air maka air dengan tingkat kekeruhan tertentu yang terletak diantara sensor dan LED akan menghalangi cahaya yang dipancarkan oleh LED, sehingga intensitas cahaya yang diterima oleh sensor akan berkurang. Perubahan intensitas cahaya yang diterima sensor masih dalam bentuk analog, sehingga dalam pengolahannya perlu dilakukan konversi ke digital. Konversi analog ke digital dilakukan oleh ADC yang sudah terintegrasi di dalam mikrokontroler ATmega8. Besaran digital ini kemudian diolah oleh mikrokontroler untuk selanjutnya dikirimkan dalam bentuk data serial ke komputer melalaui modul USBtoserial. Data yang diterima oleh komputer akan diolah oleh aplikasi yang telah dibuat untuk ditampilkan nilai dan grafiknya serta disimpan ke dalam database. Diagram blok dari sistem monitoring tingkat kekeruhan air dapat dilihat pada Gambar 2.

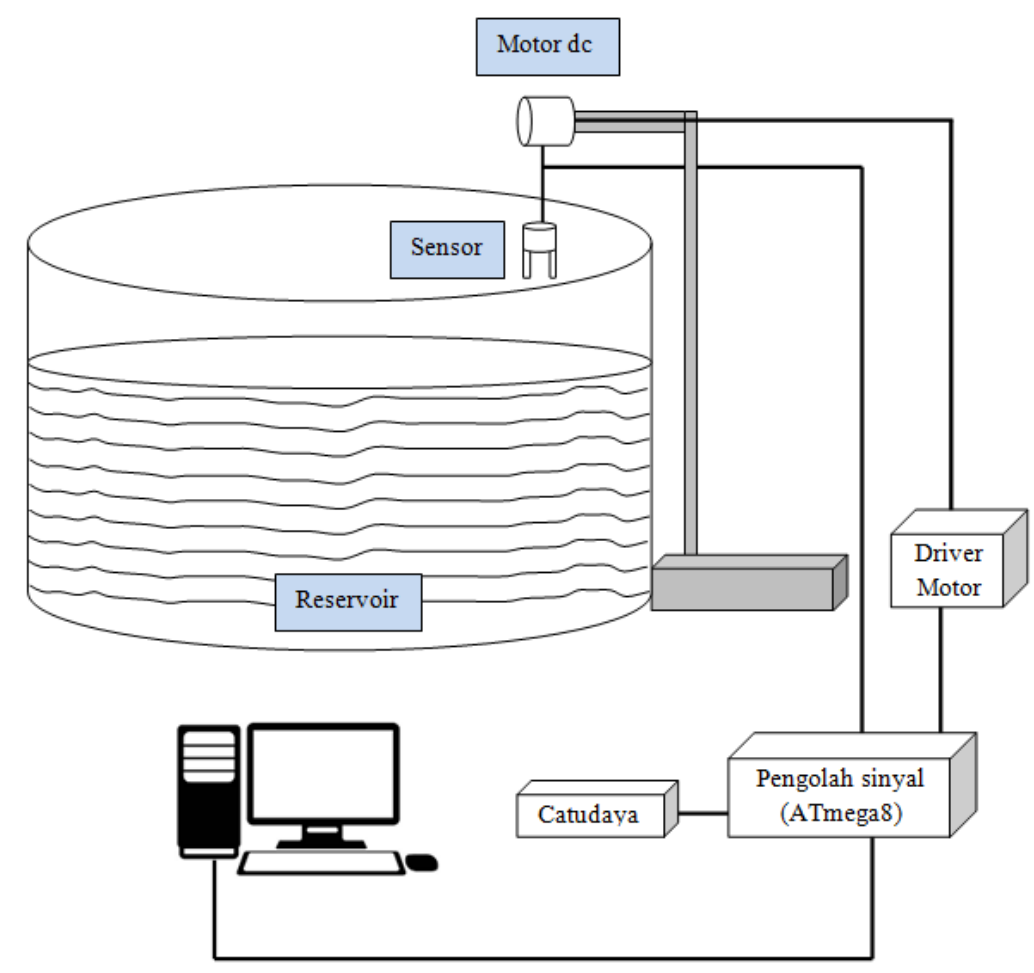

Gambar 2 Diagram blok sistem monitoring tingkat kekeruhan air

\subsection{Perancangan Perangkat Keras}

Perancangan perangkat keras sistem terdiri dari catu daya, sistem sensor TSD-10, sistem minimum ATmega8, driver motor DC, dan modul USBtoSerial. Skema rangkaian keseluruhan dari sistem monitoring kekeruhan air dapat dilihat pada Gambar 3. 


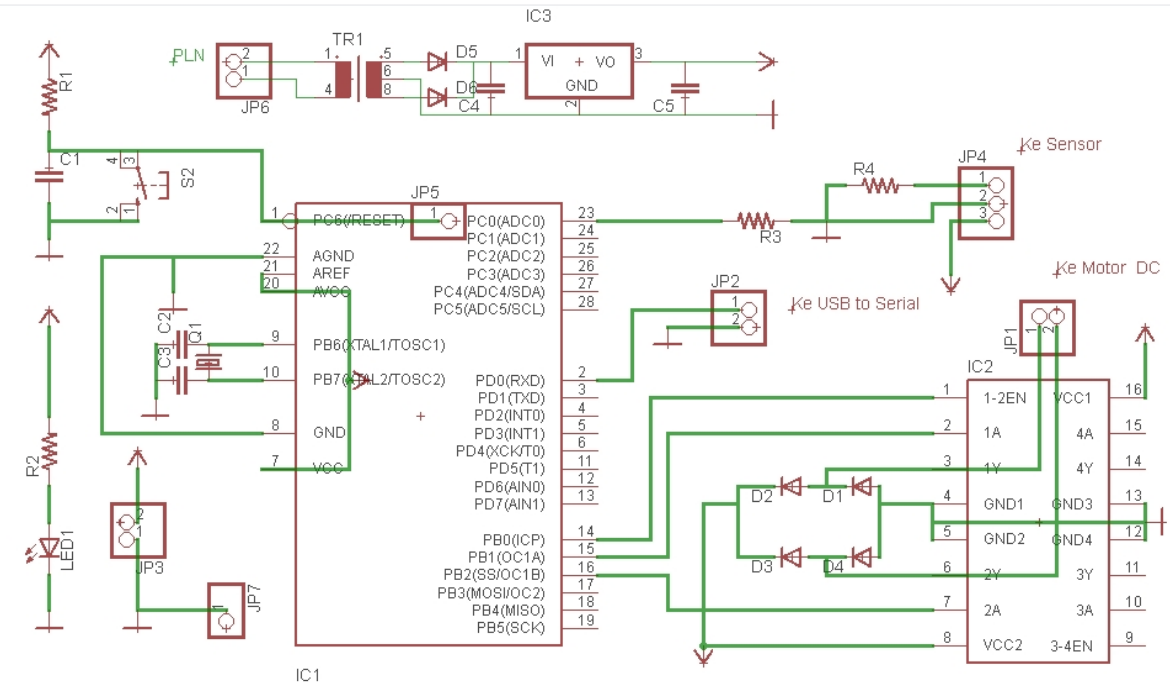

Gambar 3 Skema rangkaian keseluruhan dari sistim monitoring kekeruhan air

\subsection{Perancangan Perangkat Lunak}

Dalam perancangan sistem monitoring tingkat kekeruhan air ini ada dua jenis pemograman yang digunakan yakni pemograman pada mikrokontroler sebagai pengolah data sensor dan interface ke komputer serta pemograman pada komputer sebagai perekam data, penampil grafik dan pembuatan laporan hasil perekaman data. Untuk pengolahan data pada mikrokotroler, digunakan software BASCOM (Basic Complier) versi 2.7.0.5, sedangkan sistem GUI untuk menampilkan dan merekam data digunakan Borland Delphi 7.0. Beberapa hal yang akan ditampilkan dalam sistem GUI ini diantaranya nilai tingkat kekeruhan air, grafik tingkat kekeruhan air, rekaman data kekeruhan air, dan beberapa tombol fungsi dari sistem GUI. Sistem yang dibangun juga dapat mencetak hasil monitoring sehingga dapat dijadikan laporan tingkat kekeruhan air setiap saat.

\section{HASIL DAN DISKUSI}

Hasil perancangan sistem monitoring tingkat kekeruhan yang telah dibuat ini perlu dilakukan pengujian untuk mengetahui apakah alat yang dihasilkan dapat bekerja dan berfungsi sesuai dengan yang diinginkan. Pengujian ini dilakukan secara terpisah untuk masing-masing blok dan pengujian secara keseluruhan.

\subsection{Karakteristik Sensor TSD-10}

Pengaruh kekeruhan terhadap tegangan keluaran sensor dapat diamati dengan memvariasikan konsentrasi kekeruhan. Sampel kekeruhan cairan yang digunakan adalah air kolam dan beberapa sampel air yang telah dikeruhkan dengan tanah liat dengan konsentrasi yang berbeda. Hasil karakteristik sensor terhadap nilai kekeruhan air ditunjukan pada Gambar 4. 


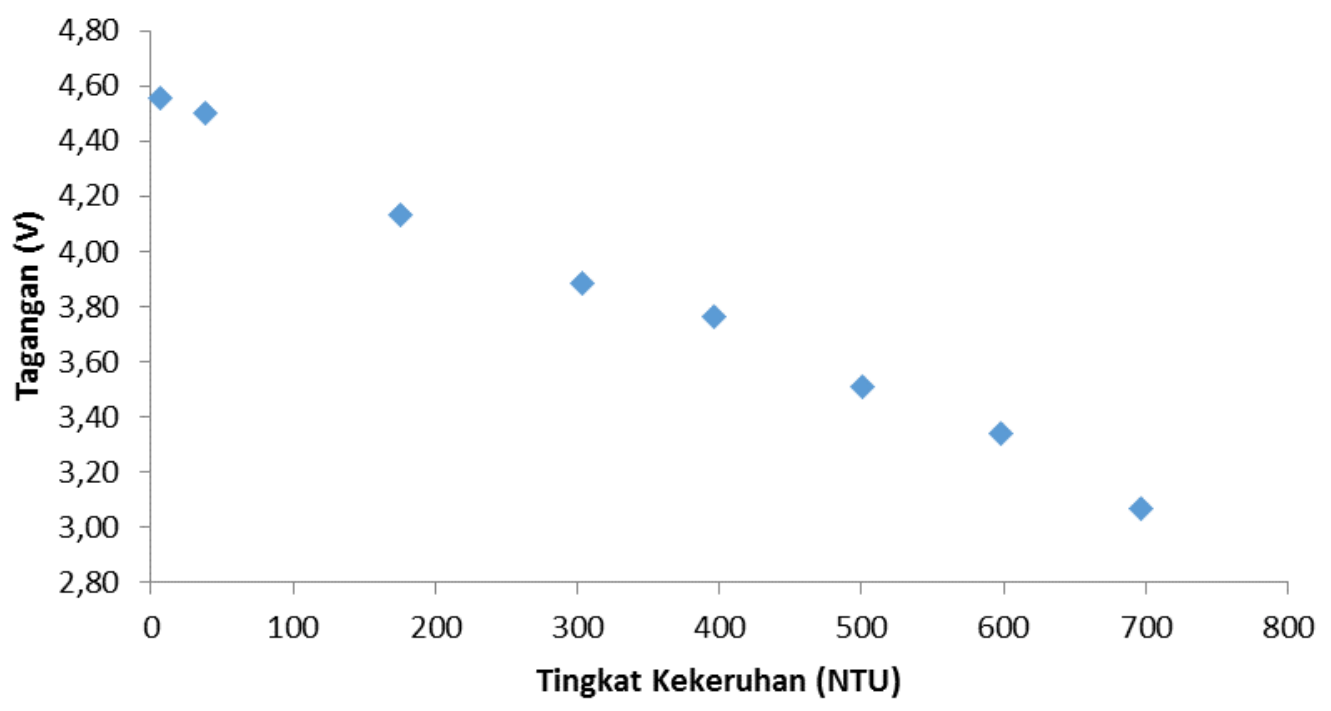

Gambar 4 Hubungan tingkat kekeruhan air dengan tegangan sensor

Dari Gambar 4 terlihat bahwa tegangan keluaran sensor semakin berkurang seiring dengan bertambahnya tingkat kekeruhan air yang diukur. Penurunan tegangan keluaran sensor berbanding lurus dengan tingkat kekeruhan air, hal ini dapat dilihat dari linieritas grafik yang terbentuk. Melalui pendekatan matematis maka diperoleh persamaan hubungan antara tegangan keluaran sensor dengan tingkat kekeruhan air yaitu $y=-0,002 x+4,554$

\subsection{Pengujian Sensor Kekeruhan}

Pengujian ketepatan alat yang dirancang dilakukan dengan membandingkan hasil pengukuran antara alat standar dengan alat yang rancang dengan beberapa sampel air. Beberapa sampel akan diuji dengan menggunakan turbidimeter digital HACH 2100N sebagai acuan di laboratorium instalasi pengolahan air Gunung Pangilun kemudian diuji dengan alat yang dirancang. Sampel yang digunakan untuk pengujian ini yaitu air kolam dan beberapa air yang dicampur dengan tanah liat. Berdasarkan hasil pengujian perbandingan pengukuran yang dilakukan dengan alat standar dan alat yang dirancang dapat dilihat pada Tabel 1.

Tabel 1 Hasil pengukuran perbandingan tingkat kekeruhan air dengan alat standar

\begin{tabular}{|c|c|c|}
\hline \multirow{2}{*}{ No } & \multicolumn{2}{|c|}{ Data Kekeruhan } \\
\cline { 2 - 3 } & $\begin{array}{c}\text { Alat Standar } \\
\text { (NTU) }\end{array}$ & $\begin{array}{c}\text { Alat Yang } \\
\text { Dibuat(NTU) }\end{array}$ \\
\hline 1 & 697 & $702,84 \pm 2,56$ \\
\hline 2 & 598 & $597,94 \pm 1,25$ \\
\hline 3 & 501 & $500,74 \pm 1,34$ \\
\hline 4 & 396 & $395,86 \pm 1,38$ \\
\hline 5 & 303 & $297,89 \pm 3,77$ \\
\hline 6 & 175 & $187,12 \pm 5,03$ \\
\hline 7 & 37,8 & $28,49 \pm 0,93$ \\
\hline 8 & 6,28 & $7,41 \pm 0,70$ \\
\hline
\end{tabular}


Berdasarkan beberapa hasil pengukuran dan perhitungan yang telah dilakukan didapatkan nilai ketepatan dari sistem bervariasi dari 75,36 \% sampai 99,99\%. Persentase ketepatan rata-rata pengukuran adalah 93,49 \% dan persentase kesalahan rata-rata pengukuran adalah $6,51 \%$. Dari data yang ada juga dapat dilihat bahwa kesalahan pengukuran cukup tinggi dan ketepatan pengukuran relatif rendah pada pengukuran dengan tingkat kekeruhan air di 37,80 NTU dan 6,28 NTU. Hal ini disebabkan salah satunya karena karakteristik sensor yang ada memiliki rentang pengukuran yang cukup besar yakni 0 NTU hingga 4000 NTU, sedangkan proses konversi perubahan analog ke digital yang dilakukan oleh ADC memiliki rentang yang cukup kecil yakni 0 hingga 1023 bit data. Selain itu juga pada tingkat kekeruhan yang kecil, intensitas cahaya yang diteruskan hampir mendekati nilai intensitas cahaya yang dipancarkan sehingga sensor fototransitor sebagai receiver tidak terlalu sensitif untuk membedakannya. Hal lain yang secara umum dapat menyebabkan terjadinya kesalahan dan kekurangtepatan pengukuran adalah faktor lingkungan seperti suhu, posisi sensor yang tidak stabil dan faktor internal dari peralatan itu sendiri karena setiap komponen memiliki nilai batas toleransinya.

\section{KESIMPULAN}

Berdasarkan hasil pengujian dan analisis data terhadap besaran yang terukur dalam sistem monitoring kekeruhan menggunakan sensor TSD-10 dapat diambil beberapa kesimpulan sebagai berikut :

1. Desain sistem terdiri dari bagian sistem sensor TSD-10, bagian blok elektronika dan sistem GUI. Bagian sistem sensor TSD-10 merupakan modul sensor yang terdiri dari transmitter berupa LED dan receiver berupa fototransistor. Bagian blok elektronika terdiri dari rangkaian catu daya, rangkaian mikrokontroler, rangkaian driver motor DC dan modul USBtoserial. Tingkat kekeruhan air akan dideteksi oleh sensor TSD-10 dan datanya diolah oleh mikrokontroler, kemudian hasilnya ditampilkan melalui aplikasi komputer serta disimpan dalam bentuk database.

2. Tegangan keluaran sensor TSD-10 berkurang seiring dengan pertambahan tingkat kekeruhan air. Pengurangan disebabkan semakin tinggi kekeruhan air maka semakin lemah intensitas cahaya yang diterima oleh fototransistor.

3. Nilai sensitivitas sensor dari hasil karakteristik sensor TSD-10 adalah 2 $\mathrm{mV} / \mathrm{NTU}$.

4. Ketepatan rata-rata pengukuran mempunyai nilai $93,49 \%$. Kesalahan relatif maksimal pengukuran adalah $24,64 \%$.

\section{DAFTAR PUSTAKA}

1. Fairuz.A.,Zubir.M., 2009,Turbidimeter Design And Analysis: A Review On Optical Fiber Sensors For The Measurement Of Water Turbidity, Sensors Vol 9, hal 83118335.

2. Hardesty. J.H., Attili B., 2010 Spectrophotometry and the Beer-Lambert Law: An Important Analytical Technique in Chemistry, Handout Department of Chemistry Collin College.

3. International Standar Organization, 1999, Water Quality-Determination Of Turbidity, ISO 7027, Geneva, Switzerland. 
4. Lambrou, TP Anastasia CC dan panayiotou, 2008, A Nephelometric Turbidity System For Monitoring Residential Dringking Water Quality, Sensor Applications Experimentation and Logistics Vol 29 hal 43-45.

5. Nuzula. N.I., Endarko., 2013, Perancangan dan Pembuatan Alat Ukur Kekeruhan Air Berbasis Mikrokotroler ATMega 8535, Jurnal Sains Dan Seni Pomits Vol. 2, No. 1, $1-5$.

6. Permenkes Nomor 492/PER/IV/ 2010 tentang Persyaratan Kualitas Air Minum.

7. Peslinof. M, 2013, Desain Alat Ukur Tingkat Kekeruhan Air Menggunakan Sistem Sensor Serat Optik, Tesis Universitas Andalas, Padang.

8. Santos. V; Guerreiro. T; Suarez. W; Faria. R; Filho.O, 2011, Evaluation of Turbidimetric and Nephelometric Techniques for Analytical Determination of NAcetylcysteine and Thiamine in Pharmaceutical Formulations Employing a LabMade Portable Microcontrolled Turbidimeter and Nephelometer, J. Braz. Chem. Soc. Vol. 22 No 10 hal 1968-1978.

9. Somasundaram. P.K., Ediosn. D.J., 2013, Monitoring Water Quality using RF Module, IJAIEM Vol 2 Issue 7 hal 220-224.

10. Hu. Y., Sun., L., Ye. S., Chen. H., Jiang. K., Pan. J., 2014, A Highly Sensitive Turbidity Sensor With Low Power Consumption, Photonic Sensor Vol 4 No 1 hal 7785 . 